\title{
BMJ Open Establishing reference costs for the health benefit packages under universal health coverage in India: cost of health services in India (CHSI) protocol
}

\author{
Shankar Prinja (D , ${ }^{1}$ Maninder Pal Singh, ${ }^{1}$ Lorna Guinness, ${ }^{2,3}$ Kavitha Rajsekar, ${ }^{4}$ \\ Balram Bhargava ${ }^{4,5}$
}

To cite: Prinja S, Singh MP, Guinness L, et al. Establishing reference costs for the health benefit packages under universal health coverage in India: cost of health services in India (CHSI) protocol. BMJ Open 2020;10:e035170. doi:10.1136/ bmjopen-2019-035170

- Prepublication history and additional material for this paper are available online. To view these files, please visit the journal online (http://dx.doi. org/10.1136/bmjopen-2019035170).

Received 23 October 2019 Revised 08 May 2020 Accepted 21 May 2020

Check for updates

(C) Author(s) (or their employer(s)) 2020. Re-use permitted under CC BY-NC. No commercial re-use. See rights and permissions. Published by BMJ.

${ }^{1}$ Department of Community Medicine and School of Public Health, Post Graduate Institute of Medical Education and Research, Chandigarh, Chandigarh, India

${ }^{2}$ Independent Researcher, Imperial College, London, UK ${ }^{3}$ Global Health and Development, London School of Hygiene \& Tropical Medicine, London, UK ${ }^{4}$ Department of Health Research, Ministry of Health \& Family welfare, New Delhi, India

${ }^{5}$ Indian Council of Medical Research, New Delhi, Delhi, India

Correspondence to

Dr Shankar Prinja;

shankarprinja@gmail.com

\section{ABSTRACT}

Introduction To achieve universal health coverage, the Government of India has introduced Ayushman Bharat - Pradhan Mantri Jan Arogya Yojana (AB - PMJAY), a large tax-funded national health insurance scheme for the provision of secondary and tertiary care services in public and private hospitals. AB - PMJAY reimburses care for 1573 health benefit packages (HBPs). HBPs are designed to cover the treatment of diseases/conditions with high incidence/prevalence or which contribute to high out-of-pocket expenditure. However, there is a dearth of reference cost data against which provider payment rates can be assessed.

Methods and analysis The CHSI (Cost of Health Services in India) study will collect cost data from 13 Indian states covering 52 public and 40 private hospitals, using a mixed economic costing methodology (top-down and bottom-up), to generate unit costs for the HBPs. States will be sampled to capture economic status, development indicators and health service utilisation heterogeneity. The public sector hospitals will be chosen at secondary and tertiary care level. One tertiary facility will be selected from each state. At secondary level, three districts per state will be selected randomly from the district composite development score ranking. The private sector hospital sample will be stratified by nature of ownership (for-profit and not-for-profit), type of city (tier 1,2 or 3) and size of the hospital (number of beds). Average costs for each HBP will be calculated across the different facility types. Multiple scenarios will be used to suggest rates which could be negotiated with the providers. Overall, the study will provide economic cost data for price setting, strategic purchasing, health technology assessment and a national cost database of India.

Ethics and dissemination The approval has been obtained from the Institutional Ethics Committee and Institutional Collaborative Committee of the Post Graduate Institute of Medical Education andResearch, Chandigarh, India. The results shall be disseminated in conferences and peer-reviewed articles.

\section{INTRODUCTION}

To turn the vision of universal health coverage (UHC) into reality and provide accessible and affordable healthcare, the Government
Strengths and limitations of this study

- First nationally representative costing study in India, generating cost estimates for 1393 health benefit packages in the public and private sector.

- Using standard economic costing methodology (mix of top-down and bottom-up approach).

- The study results will inform setting provider payment rates, developing a cost function and national cost database.

- In the absence of electronic health records, it is not feasible to capture disease-specific data.

- Due to the lack of disaggregated data, pure bottomup costing will not be possible.

of India has launched the Ayushman Bharat scheme. Ayushman Bharat envisages achieving UHC through the provision of free primary care services at the newly upgraded health and wellness centres (HWCs). Further, there is a provision of a tax-funded national health insurance scheme, Ayushman Bharat-Pradhan Mantri Jan Arogya Yojana (AB - PMJAY) to provide financial protection to beneficiaries seeking care at secondary and tertiary public and private healthcare facilities. AB - PMJAY will provide insurance coverage of 500000 Indian rupees (INR) (US\$ 7000 approximately) per family per year, to more than 100 million vulnerable families. It includes reimbursement for the treatment of 1573 health benefit packages (HBPs). HBPs are designed to cover diseases/conditions with high incidence/prevalence and the diseases which contribute to high levels of out-ofpocket (OOP) expenditure. ${ }^{1}$ In parallel, the Government of India has directed its health technology agency-Health Technology Assessment India (HTAIn)- to generate evidence to inform what should be included as HBPs under AB - PMJAY. ${ }^{2}$ 
Within AB - PMJAY, empanelled hospitals and providers will be paid based on predefined HBPs. The reimbursement rates have been determined through a consultative process with experts and a review of existing health insurance schemes due to lack of reference cost data in India. A problem with such charge-based reimbursement rates is that they do not capture the actual cost and resource use. The rates then reflect the business model of the healthcare provider and the rate they believe they can charge given who is paying for the service. ${ }^{3}$

While there is relatively significant data on out-ofpocket expenditure in India, there are a limited number of studies on the health system cost. ${ }^{45}$ Published cost studies include costing of surgical procedures, ${ }^{6}$ disease or condition-specific treatments ${ }^{7-9}$ and public healthcare facility costs. ${ }^{10-12}$ These are not comprehensive and do not systematically cover all healthcare services and healthcare providers-most significantly the absence of the private sector. Among middle-income countries, Thailand's national cost database has shown how cost information can be used in both economic evaluations and to inform price-setting for strategic purchasing and cost containment. ${ }^{13}$ India is yet to develop a similar nationallevel system of costing for public and private facilities. The first step in this direction has been the establishment of the national cost database which provides unit cost estimates for outpatient visits and inpatient stays for primary and secondary levels of the public health system ${ }^{14}$ and uses a cost function approach to predict unit costs for the district level and below. ${ }^{15}$ Building on this, HTAIn has commissioned a national costing study entitled 'Cost of Health Services in India' (CHSI) to inform reimbursement rates of HBPs under $\mathrm{AB}$ - PMJAY, and for use in economic evaluations.

This paper aims to document the methodology for CHSI study's health systems cost estimation for India. The paper describes a standard costing methodology for India for measuring the cost of preselected HBPs in public and private hospitals. Further, the cost data generated by the CHSI study, will add to the national cost database and generate cost function for tertiary and secondary level public and private hospitals in India.

\section{METHODOLOGY}

\section{Study design}

The costing methodology follows standard principles for healthcare costing ${ }^{16-18}$ and builds on experience from previous work by Post Graduate Institute of Medical Education and Research (PGIMER) and its partners. ${ }^{1012} 19$ Initially, Ayushman Bharat covered 1393 HBPs under the insurance policy. In 2019, National Health Authority (NHA) revised the nomenclature and number of the HBPs. So, the total HBPs changed to 1573 . This change is due to; first, inclusion of more diseases or conditions which were earlier not covered like heart catheterisation, chronic hepatitis, diabetic foot, triple valve procedure, gastrectomy, and so on. Second, in earlier version, a single
HBP with single reimbursement rate covered a group of health conditions. However, based on the expert consultations and experience from first year it is found that the amount of resources used are different. Hence, to optimise reimbursement rates in terms of resource consumption, that is, cost of treating individual disease conditions, these are split into separate HBPs. For example, HBP for surgical correction of congenital heart diseases is stratified into three categories (I, II and III) with differential reimbursement prices. Third, since the number of HBPs are increased to cover more health conditions, as well as made more specific, so the unspecified HBPs are omitted. Finally, change in number of HBPs is to make these congruous with the International Classification of Diseases, $10^{\text {th }}$ Revision. We would like to clarify that the change in number of HBPs does not imply a change in number of individual services (such as outpatient care, inpatient care, and so on) within the provision of services for a given HBP.

Accordingly, the CHSI study proposes to estimate the average unit cost of 1573 HBPs and the individual healthcare services which constitute these HBPs. All the resources used for delivering a service, irrespective of who pays for it, are identified, measured and accounted for. The study will take a provider perspective and include all the costs required to deliver the HBPs, in both public and private healthcare facilities. Also, the study will include an OOP expenditure on drugs and consumables by the patient in the case of public hospitals due to nonavailability. However, to value these resources purchased by the patients in the form of market transactions, we will use a provider perspective instead of market prices, that is, applied provider prices if the same is purchased by the hospital. This approach is considered appropriate as it then reflects the counterfactual scenario, where the hospital provides cashless service to the patient for a given HBP and gets reimbursed by the insurance agency for the cost incurred. A detailed description of the cost data to be collected is provided in the data collection section. The process of cost data collection will also be documented at each site to learn lessons and help improve costing processes in the future.

\section{Sampling of facilities}

Healthcare delivery costs vary across states and facilities due to variation in service delivery patterns, local prices of various resources, rental prices of space and human resources wage rates. ${ }^{12} 19$ Costs are also influenced by health workforce density and determinants of healthcareseeking behaviour. ${ }^{20-22}$ Therefore, to obtain representative costs of AB - PMJAY HBPs, secondary and tertiary hospitals in both the public and private sectors will be sampled. Guidance for the sampling of facility-level costing studies is limited. ${ }^{23}$ In the absence of methods to calculate an appropriate sample size for such skewed data, a multistage stratified sampling method will be used. The states were selected to represent the heterogeneity based on geography, health indicators, net state domestic 
Table $1 \mathrm{CHSI}$ study: sampling framework

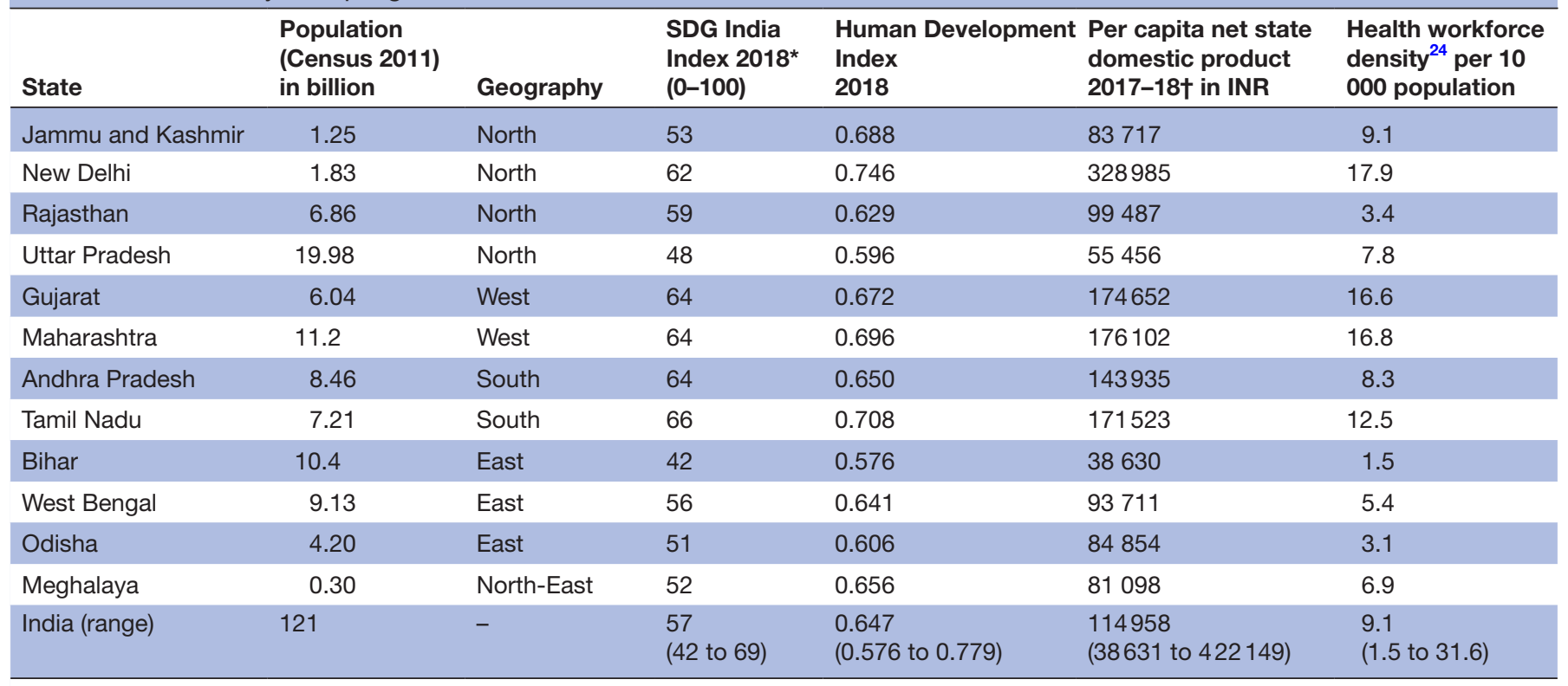

*SDG: Sustainable Development Goals India Index NITI Aayog 2018.

tReserve Bank of India.

$\mathrm{CHSI}$, Cost of Health Services in India; INR, Indian rupees.

product (NSDP) and health workforce density. ${ }^{24}$ Table 1 shows population, geography, Sustainable Development Goals India Index, Human Development Index, percapita NSDP and health workforce density (per 10000 population) for sampled states and compare it with the national average of India. The states included in the study will be Jammu and Kashmir, Chandigarh, New Delhi, Rajasthan, Uttar Pradesh, Bihar, West Bengal, Gujarat, Maharashtra, Andhra Pradesh, Tamil Nadu and Meghalaya. Within each state, a tertiary level medical institution will be chosen. The choice of the tertiary level healthcare facility will be guided by the availability of specialities to maximise the number of HBPs that can be costed across the sample. At the secondary care level, costing will be done at three district hospitals in each state. The districts will be randomly selected from each of the three tertiles of the district composite development score ranking. ${ }^{25}$ This index is based on an aggregation of socioeconomic, demographic and health service usage indicators. Overall, a total of 52 public health facilities will be selected including 13 public tertiary care hospitals and 39 district hospitals providing secondary care.

The choice of sampling methods for the private sector is complicated for multiple reasons. First, there is no single comprehensive updated line list of all medical facilities or hospitals in the private sector. Second, the heterogeneity of the private sector in terms of its resources and cost of care further complicates the methodology of sampling. Third, it is not possible to survey facilities to establish the different levels of quality of care across providers. In the absence of any formal accreditation mechanism or implementation of clinical establishment act, we will use the list of empanelled hospitals as part of the national-level
Rashtriya Swasthya Bima Yojana (RSBY) and state-specific publicly financed health insurance schemes to select private hospitals. We will agree a sampling approach with experts from the NHA nodal agency for implementation of PMJAY at national-level that reflects market structure for the private sector. For each hospital, we will obtain the data on location, ownership and number of beds of the hospitals. From this list, we will select a sample of 40 private hospitals from 13 states considering the type of ownership, location and size of the hospital. Since nearly three-fourth of the total private sector hospitals are reported to be for-profit, ${ }^{26}$ a probability proportion to size approach will be chosen to select hospitals by type of ownership. Second, hospitals will be chosen from different tiers of cities in each of the chosen 13 states. Third, the hospitals will be stratified by size in terms of hospital beds (figure 1).

\section{Costing approach}

Several approaches to costing have been recommended in the literature, with each serving a different purpose and with different advantages and disadvantages. ${ }^{27} 28$ While normative costing takes an approach of costing the provision of services as per a standard protocol, microcosting approaches estimate the cost of services as per actual practices of provision. There are two ways in which micro-costing is carried out, top-down and bottom-up. A top-down approach uses retrospective data of healthcare expenditures and divides the total expenditure by the services provided in the given period. It does not have distinct steps for the measurement and valuation of resource usage. A bottom-up approach allows much greater disaggregation of the cost data, tends to be more 


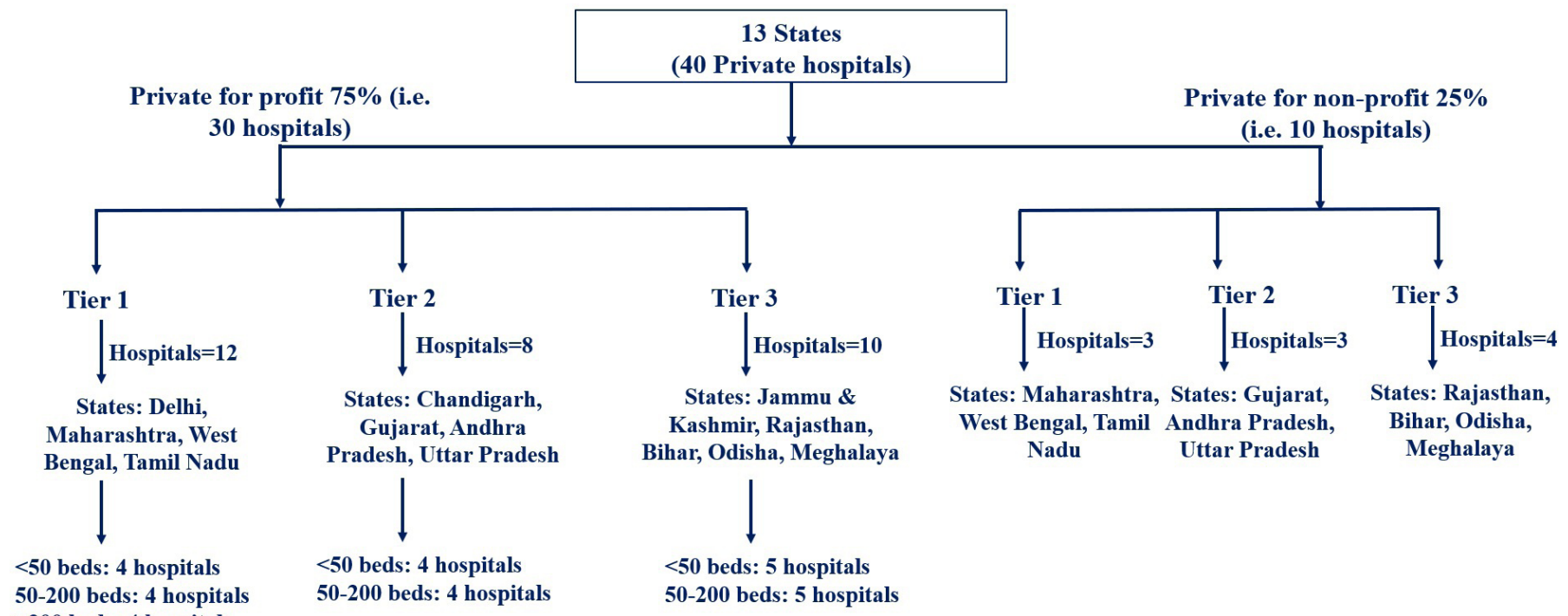

>200 beds: 4 hospitals

Figure 1 Sampling technique for private sector.

accurate but more time-consuming. ${ }^{21}$ Previous cost studies in India have used mixed approaches. ${ }^{7}$ Disaggregated data is useful for price-setting as it generates information on the cost of each input and allows for the estimation of different combinations of average cost, so that a decision regarding what should be included in the price may be taken. ${ }^{22}$ Combining top-down approaches with bottom-up costing is also a common method applied in cost studies. ${ }^{18} 28$ This approach can achieve a sufficient level of disaggregation to inform price-setting and therefore the CHSI study followed this approach.

The study will estimate the following unit costs for individual specialities-the cost per outpatient consultation, per inpatient bed-day, per intensive care bedday, per diagnostic test, per ancillary service, and so on using top-down and per individual surgery using mixed micro-costing. To estimate HBP costs, each HBP will be defined as a package of these service units, for example, numbers of outpatient visits, inpatient days and intensive care days. Only this approach is feasible as data on the use of input resources (drugs, consumables, and so on) as per morbidity profile of the patients is not maintained in Indian settings. The input costs incurred for delivering

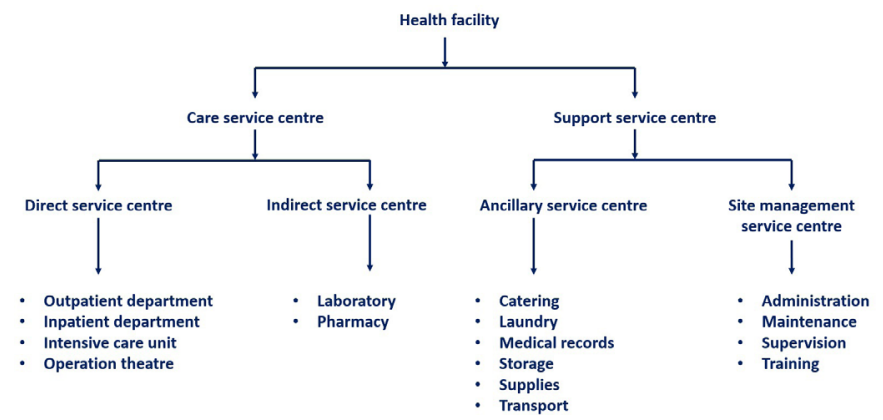

Figure 2 Type of service centres to be costed at different level of facilities. All heads may not be applicable at both tertiary and secondary level health facilities. outpatient services will be apportioned based on the total number of outpatient consultations. For inpatient and intensive care services, input costs will be apportioned using a factor of the total number of patients and an average length of stay. However, to calculate the unit cost of various surgical interventions in the operation theatre, a mixed approach will be used. The data on the use of input resources (equipment, drugs and consumables) for each surgical intervention will be captured separately using a bottom-up approach. The cost of human resources, infrastructure, furniture and overheads will be estimated using the top-down approach. The average time to conduct a procedure will be obtained through expert opinion (surgeons, consultants, and so on). Data on resources used and prices will be collected for 1 year. The methods are adapted from the Introduction to the Integrated Management of Newborn and Childhood Illness (IMNCI) Multi-Country Evaluation Costing guidelines and The Joint United Nations Programme on HIV/AIDS (UNAIDS) guidelines for estimating health system costs. ${ }^{23} 25$ The cost data collection tools will be adapted and developed from previous Indian costing studies. ${ }^{101219}$ (online supplementary material table S1, S2, S3) The reference year for the data collection period will be from $1^{\text {st }}$ April 2017 to $31^{\text {st }}$ March 2018. The period of data collection is phased for 2.5 years. The tertiary public hospitals data collection will be phased in two parts-September 2018 to April 2019, followed by February 2020 to September 2020. The data collection for district hospitals and private hospitals will be undertaken from May 2019 to January 2020.

\section{Data collection Identifying input resources}

An inventory of cost centres as outlined in figure 2 will be prepared for each facility. This includes care service centres (providing direct patient care) and support 
service centres. The care service centres are further classified into direct and indirect service centres.

Each service centre that produces a product or output towards care services will be first identified and its output defined. For instance, the output of an inpatient ward is the number of hospitalisations; while the output of an operation theatre is number of surgical procedures performed. On defining output, the quantity of output produced in 1 year at the service centre will be extracted from the routine physical or management information system (MIS) records at the institution. For the support centres, a unit of output will also be defined. Once service centres and the type of output have been determined, the inputs used to produce the output for each service centre will be identified and their quantity will be measured. (table 2)

Inputs include a wide range of resources, divided into fixed and variable using a standard classification system across all facilities. The variable resources will be subdivided into drugs, consumables, utility and overheads such as electricity, water, maintenance, and so on. Fixed resources will be subdivided into human resources, capital space, equipment, furniture, and so on. Staff time for each service centre is determined through staff

Table 2 Cost centre inputs

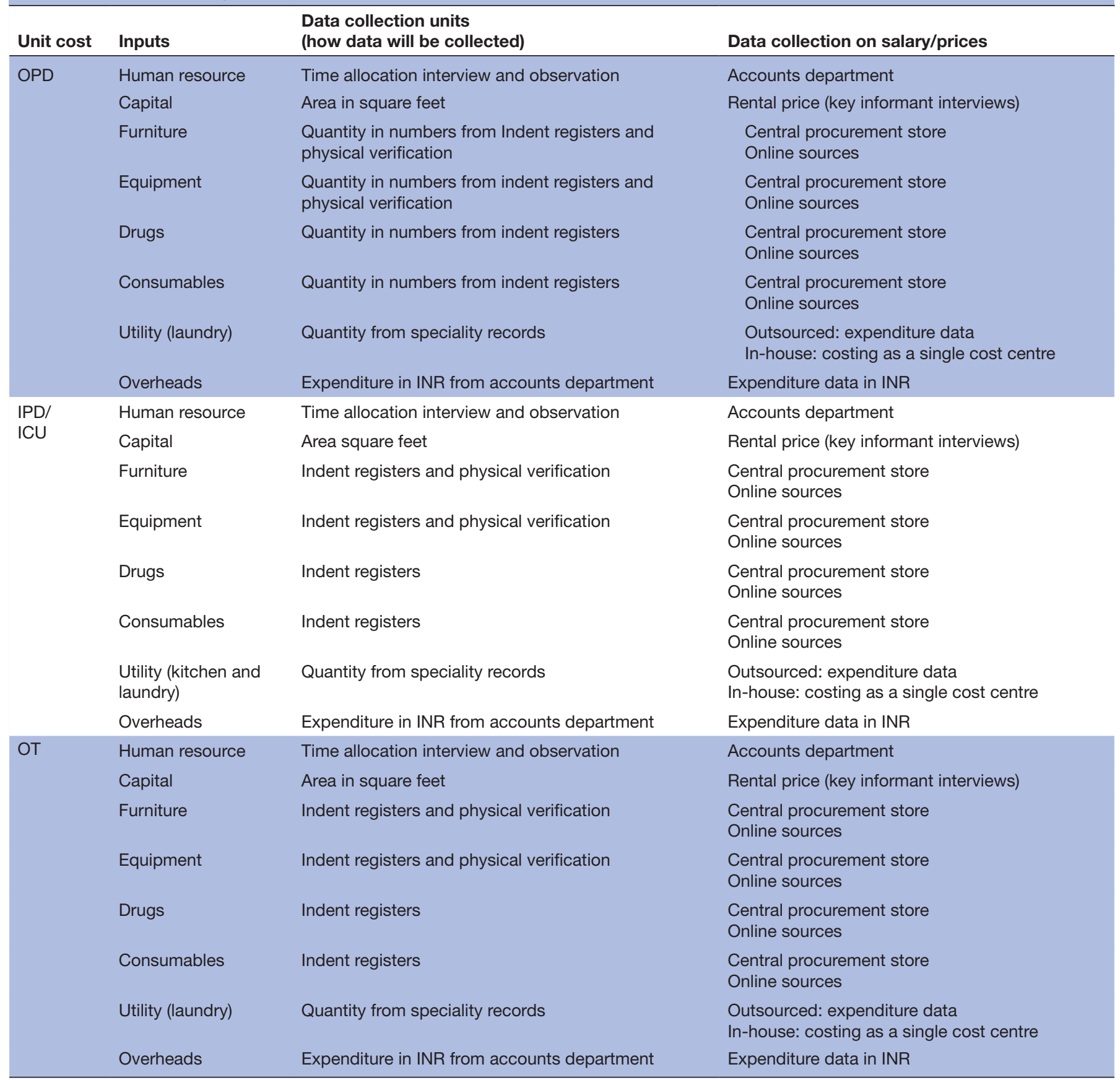

ICU, intensive care unit; INR, Indian rupees; IPD, inpatient department; OPD, outpatient department; OT, operation theatre. 
interviews using a pretested semi-structured interview schedule, used in earlier costing studies. ${ }^{11} 1219$ (online supplementary material; table 2 section 9) There are different cadres of staff including consultants, nursing staff, technicians, paramedical staff, housekeeping and administrative support, providing services in a service centre. For each service centre, a minimum of $25 \%$ of staff from each cadre of staff will be interviewed to ascertain the time spent by each cadre in all the individual activities like patient care, teaching, administration, meetings, workshop/conferences, research, outreach, and so on. A line list of each cadre of staff working at a service centre will be obtained. Subsequently, $25 \%$ of the staff will be randomly selected and interviewed. In case for a service centre or staff cadre if the number of staff members is less than four, one individual will be randomly selected and interviewed. The recall period is for 1 month which will be extrapolated to 1 year.

All resources used for a given surgery or procedure for treating a specific condition which are not provided by the public hospitals will be obtained from the healthcare providers (consultants, nurses, pharmacist or laboratory technicians) and included in cost estimation. This will include OOP expenditure incurred by patients on resources such as medicines, consumables or diagnostics. This information is important for deriving cost for setting the provider payments for HBPs.

\section{Valuing resources used}

The monetary value for each item will be based on the current financial price. Since the purpose of the CHSI study is to inform price-setting under the $\mathrm{AB}$ - PMJAY scheme, the current procurement prices of the hospitals for medicines, consumables, equipment and other items will be used. Gross salaries of individual human resources will be obtained using the payslips from the accounts department. The rental value of government land, when leased to private vendors, will be used to estimate the opportunity cost of the space used in each cost centre. In addition, this will be supplemented with a key-informant survey to obtain rental prices in the neighbourhood of the hospital. For estimating the cost of building and space, the floor area will be multiplied with rental value. The capital costs such as equipment, furniture, and so on, will be annualised using a standard discount rate of $3 \%$ as recommended in international and Indian HTA guidelines. ${ }^{1629}$ All costs will be in the current Indian rupees.

\section{Data analysis}

Total and unit costs for each service centre and speciality

The annual cost of each recurrent input will be calculated by multiplying the unit price by the number of consumed inputs for a given time period within the service or support centre. All input costs for the care or support centre will then be summed to obtain the total cost. At each facility, total cost and unit cost will be generated for each cost centre. The cost of joint resources will be allocated based on appropriate apportioning statistics.(table 3) (online supplementary figure S1)

Finally, the allocated cost of the support and indirect service centres such as laundry, kitchen, and so on, will be added to the costs of the respective care centre to obtain a total annual cost of providing each service (care and speciality). These costs will be allocated to each of the care centres based on utility and number of patients. The CHSI study will estimate the following unit costs for individual specialities at public and private sector hospitals, for both secondary and tertiary level of healthcare-the cost per outpatient consultation, per inpatient bed-day, per individual surgery, per diagnostic test, per ancillary service, and so on. The speciality-wise unit cost of outpatient care will be estimated as a ratio of total annual costs for outpatient care and total number of outpatient visits for respective specialities in reference year period. Similarly, the unit cost for inpatient care will be calculated as the ratio of total inpatient costs and total bed-days of admission for each speciality. The unit cost per procedure for the operating theatre will be calculated as the ratio of the total cost of inputs like human resource, equipment, drugs, capital, and so on, used for specific procedures to the number of each specific procedure.

\section{Disease-specific or HBP cost: using cost data for pricing}

The estimates derived from the CHSI cost data will include unit cost per outpatient consultation, per diagnostic test, per procedure, per bed-day cost (intensive care unit or inpatient ward) and per follow-up consultation. These estimates will then be used to derive unit cost of HBPs within the AB - PMJAY.(figure 3) The HBPs under a speciality will be of two types, procedures performed in the facility during the reference year and those not performed. For the estimation of these HBPs, data on average outpatient department (OPD) visits, diagnostics, procedure time and average length of stay in intensive care unit/inpatient department (IPD) will be collected based on the expert opinion. For the estimation of the cost of procedures performed during the reference year, primary data will be collected. However, the cost of procedures which would not have been conducted during the reference period, would be estimated by using unit cost per functional operation theatre hour. All other unit costs such as (OPD, IPD and diagnostics) would remain the same as in the case of procedures conducted in the reference year. For pre-hospitalisation and follow-up outpatient visits same unit cost will be used. This individual service specific costs will add up to about 32500 endpoints for tertiary public hospitals. (online supplementary material 2) For each disease, the treatment pathway will be described and cost data from the CHSI study will be applied to estimate the average cost of the hospital component of treatment. The input costs in the HBPs will be divided into fixed and variable costs to derive package rates at different levels of reimbursement of fixed cost at 100\%, $75 \%, 50 \%$ and $33 \%$, along with $100 \%$ variable cost. 
Table 3 Apportioning statistics for joint resources

\begin{tabular}{lll}
\hline Input resources & $\begin{array}{l}\text { Level of data } \\
\text { collection }\end{array}$ & Allocation level \\
\hline Human resource & Speciality & $\begin{array}{l}\text { Cost centre (OPD/IPD/ } \\
\text { ICU/OT) }\end{array}$ \\
\hline
\end{tabular}

\section{Apportioning statistics}

Based on time allocation and observation, salary will be apportioned to each cost centre

For shared human resources like ward boys, salary will be allocated to the respective departments based on the number of patients in each department

Output OPD: number of patients

ICU/IPD: number of patients $\times$ average length of stay

OT: weighted average of number of procedures $x$ time per procedure

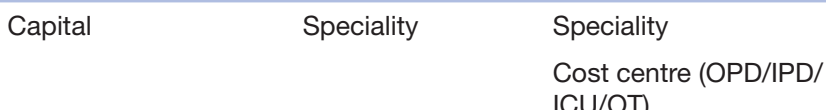

ICU/OT)

Total space of speciality in the facility based on area square feet

Total space of cost centre in the speciality based on area square feet Common areas like waiting areas, corridors, and so on will be allocated based on number of patients in each department

Output OPD: number of patients

ICU/IPD: number of patients $\times$ average length of stay

OT: weighted average of number of procedures $\times$ time per procedure

\begin{tabular}{lll} 
Furniture & Speciality & $\begin{array}{l}\text { Cost centre (OPD/IPD/ } \\
\text { ICU/OT) }\end{array}$ \\
& Output \\
\hline Equipment & Speciality & Cost centre
\end{tabular}

Output

Furniture used in each cost centre

Furniture in common areas like waiting areas, corridors, and so on will be allocated based on number of patients in each department

OPD: number of patients

ICU/IPD: number of patients $x$ average length of stay

OT: weighted average of number of procedures $x$ time per procedure

Equipments used in each cost centre

Equipments in common areas like waiting areas, corridors, and so on will be allocated based on number of patients in each department

OPD: number of patients

ICU/IPD: number of patients $\times$ average length of stay

OT: equipment use for each procedure will be estimated; then allocation

based on weighted average of number of procedures $\times$ time per procedure

\begin{tabular}{|c|c|c|c|}
\hline \multirow{2}{*}{$\begin{array}{l}\text { Drugs and } \\
\text { consumables }\end{array}$} & \multirow[t]{2}{*}{ Speciality } & Cost centre & Drugs and consumables used in each cost centre \\
\hline & & Output & $\begin{array}{l}\text { OPD: number of patients } \\
\text { ICU/IPD: number of patients } \times \text { average length of stay } \\
\text { OT: drugs and consumables used for each procedure will be estimated } \\
\text { followed by apportioning on number of procedures }\end{array}$ \\
\hline \multirow{2}{*}{$\begin{array}{l}\text { Utility (kitchen and } \\
\text { laundry) }\end{array}$} & \multirow[t]{2}{*}{ Speciality } & Cost centre & Expenditure on each cost centre \\
\hline & & Output & $\begin{array}{l}\text { OPD: number of patients } \\
\text { ICU/IPD: number of patients } \times \text { average length of stay } \\
\text { OT: number of procedures }\end{array}$ \\
\hline
\end{tabular}

\section{Overheads}

Electricity

Facility Speciality

Cost centre

Output

$\begin{array}{llll}\text { Water/gas/kerosene } & \text { Facility } & \begin{array}{l}\text { Speciality } \\ \text { Cost centre } \\ \text { Output }\end{array} & \begin{array}{l}\text { Cost will be allocated based on proportion of area } \\ \text { Cost will be allocated to each cost centre by proportion of area } \\ \text { OPD: number of patients } \\ \text { ICU/IPD: number of patients } \times \text { average length of stay } \\ \text { OT: weighted average of number of procedures } \times \text { time per procedure }\end{array} \\ \begin{array}{lll}\text { Telephone/Internet/ } \\ \text { security }\end{array} & \text { Facility } & \begin{array}{l}\text { Speciality } \\ \text { Cost centre } \\ \text { Output }\end{array} & \begin{array}{l}\text { Cost will be allocated based on proportion of area } \\ \text { Cost will be allocated to each cost centre by proportion of area } \\ \text { OPD: number of patients }\end{array} \\ & \text { ICU/IPD: number of patients } \times \text { average length of stay } \\ & \text { OT: number of procedures }\end{array}$

OPD: number of patients

ICU/IPD: number of patients $\times$ average length of stay

OT: weighted average of number of procedures $\times$ time per procedure Cost will be allocated based on proportion of area

OPD: number of patients

ICU/IPD: number of patients $\times$ average length of stay

Dighted average of number of procedures $x$ time per procedure

Continued 


\begin{tabular}{clll}
\hline Table 3 Continued & & \\
\hline \multirow{2}{*}{ Input resources } & $\begin{array}{l}\text { Level of data } \\
\text { collection }\end{array}$ & Allocation level & Apportioning statistics \\
\hline Biomedical waste & Facility & Speciality & Per bed-day expenditure multiplied by number of beds in the speciality \\
& & Cost centre & Based on number of bins in each cost centre \\
& & OPD: number of patients \\
& & ICU/IPD: number of patients $\times$ average length of stay \\
& & OT: weighted average of number of procedures $\times$ time per procedure
\end{tabular}

ICU, intensive care unit; IPD, inpatient department; OPD, outpatient department; OT, operation theatre.

The CHSI cost data will be used to develop a statistical cost function to explore the determinants of cost. A cost function is defined as mathematical relationship between the outputs produced and the cost (or quantity) of resources used to produce it. The present authors have already used an average cost function approach to predict the outpatient and inpatient costs for India. ${ }^{15}$ The principles of this cost function will be applied using the CHSI data to estimate a cost function for HBP costs. The CHSI cost data will help develop an HBP-specific cost function for tertiary and secondary level public and private hospitals.

\section{Ethics and dissemination}

This study is approved by the Institutional Ethics Committee (IEC) vide letter no. PGI/IEC/2018/00125A and Institutional Collaborative Committee vide letter no. 79/30-Edu13/111273 of Post Graduate Institute of Medical Education andResearch, Chandigarh, India.

The study results will be published in peer-reviewed journals and presented to the policymakers at national level. Further, the cost estimates generated by the study

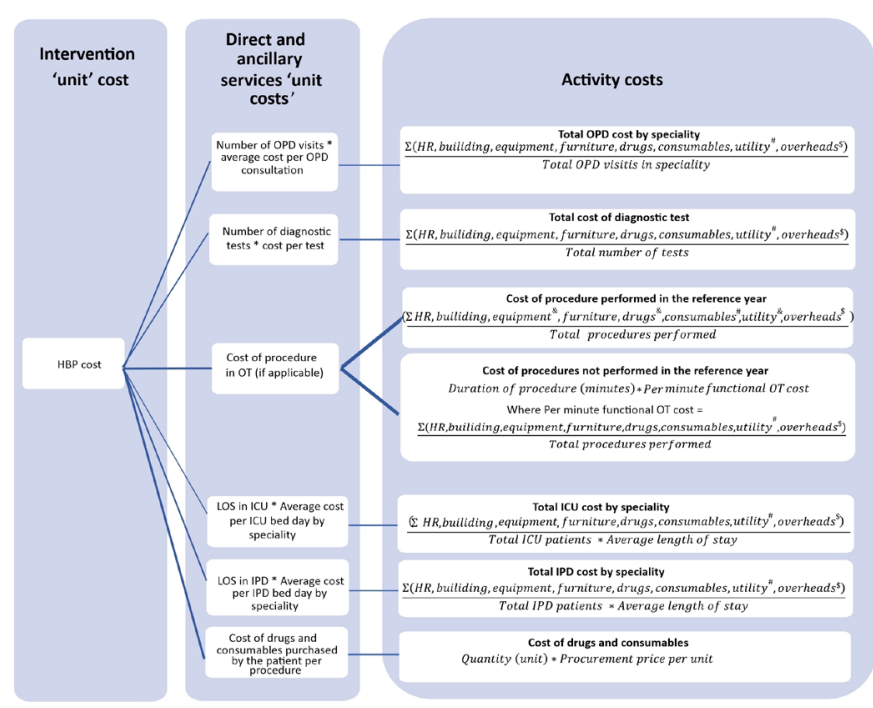

Figure 3 Unit cost typology of HBPs. \#, utility include: kitchen and laundry; \$, overheads include: electricity, water,gas, security, biomedical waste, maintenance, and so on; @, equipment, drugs,consumables allocated based on use per line item in each operation theatre procedure; HBP, health benefit package; HR, human resources; ICU, intensive care unit; IPD, inpatient department; LOS, length of stay; OPD, outpatient department; OT, operation theatre. will be integrated to National Health System Cost Database for India providing information to policymakers and researchers.

\section{Patient and public involvement}

No patient involved.

\section{DISCUSSION}

\section{Expected outcomes of the research and policy implications}

Establishing reimbursement rates is a strategic decision made by the purchaser. The Government of India will be involved in negotiations with healthcare providers to agree on case-based reimbursement rates under AB - PMJAY. The existing set of provider payment rates of $\mathrm{AB}$ - PMJAY which have been set based on review of existing insurance schemes, as well as consultative exercise, has met significant criticism from the private sector. Hence, there is an acute demand for data on the determinants of cost of care so that HBPs prices can be developed based on scientific evidence.

The CHSI study data can inform the policymakers in setting reimbursement rates by providing the full economic cost information and facilitate the Government's understanding of the prices proposed by healthcare providers. This study will provide the first nationally representative comprehensive costing data-in terms of geographical coverage, condition coverage, levels of care and type of healthcare providers. It will use standard costing methods to determine the cost of 1573 HBPs under the AB - PMJAY and incorporate diverse public and private healthcare facilities. Based on discussion and consultation with policymakers and programme managers, the CHSI study proposes a range of different pricing scenarios for setting of reimbursement prices by presenting disaggregated analysis of unit costs for each disease or package. Each scenario consists of full variable cost and different shares of fixed cost $(100 \%, 75 \%, 50 \%$ and $33 \%)$.

The study estimates will help to broaden the existing health system cost database. ${ }^{150}$ Further, the current study will help in deriving a cost function to predict the cost of various healthcare services at different levels of India's healthcare system, thus reducing the need for recurrent primary data collection. It will further fulfil the needs of HTA in India by providing cost estimates, help policymakers understand the present costs of delivering various services in the public healthcare system and support the 
better management of financial resources. These cost data can help in developing a transparent and evidence-based decision and policymaking environment to facilitate re-allocation of resources appropriately, effectively and efficiently.

\section{Limitations}

We would like to note a few limitations of our study. First, the mixed micro-costing approach, a combination of topdown and bottom-up will be used due to limited availability of disaggregated data at identified cost centres. Moreover, electronic health records are absent in the Indian healthcare system. Hence, it is not feasible to capture diseasespecific data. As a result, speciality-specific inputs will be apportioned to individual HBPs based on suitable apportioning statistics which may reduce the accuracy in the cost estimation. Furthermore, since there are no standard treatment guidelines available for most of the HBPs, expert opinion will be obtained to define treatment protocol for all HBPs and this may not reflect current practice at all facilities. The Indian Council of Medical Research (ICMR) and Department of Health Research (DHR) are defining standard treatment workflows (STWs) for HBPs. Once these STWs becomes available, the estimates of the CHSI study will be revised.

Acknowledgements We are grateful to Dr Sedona Sweeney, Assistant Professor in Health Economics, London School of Hygiene \& Tropical Medicine, for her useful comments and inputs as part of her external independent review of the Cost of Health Services in India (CHSI) study.

Contributors Study conception: SP, BB and KR. Study design: SP. Study tools: SP and MPS. Writing (first draft): MPS, SP and LG. Writing (review and editing): SP, MPS, $L G, K R$ and $B B$.

Funding The study is funded by the Department of Health Research, Ministry of Health and Family Welfare, Government of India.

\section{Competing interests None declared.}

Patient and public involvement Patients and/or the public were not involved in the design, or conduct, or reporting, or dissemination plans of this research.

Patient consent for publication Not required.

Provenance and peer review Not commissioned; externally peer reviewed.

Open access This is an open access article distributed in accordance with the Creative Commons Attribution Non Commercial (CC BY-NC 4.0) license, which permits others to distribute, remix, adapt, build upon this work non-commercially, and license their derivative works on different terms, provided the original work is properly cited, appropriate credit is given, any changes made indicated, and the use is non-commercial. See: http://creativecommons.org/licenses/by-nc/4.0/.

\section{ORCID iD}

Shankar Prinja http://orcid.org/0000-0001-7396-1273

\section{REFERENCES}

1 National Health Authority. Ayushman Bharat -Pradhan Mantri Jan Aarogya Yojana (AB - PMJAY), 2019. Available: http://pib.nic.in/ newsite/PrintRelease.aspx?relid=183624 [Accessed 24 Aug 2019].

2 Gauba V, Jain S, Rajshekar K, et al. Department of health researchhealth technology assessment (DHR-HTA) database: national prospective register of studies under HTAln. Indian J Med Res 2018;148:258-61.

3 Arora V, Moriates $\mathrm{C}$, Shah $\mathrm{N}$. The challenge of understanding health care costs and charges. AMA J Ethics 2015;17:1046-52.

4 Prinja S, Downey LE, Gauba VK, et al. Health technology assessment for policy making in India: current scenario and way forward. Pharmacoecon Open 2018;2:1-3.
5 Prinja S, Chauhan AS, Angell B, et al. A systematic review of the state of economic evaluation for health care in India. Appl Health Econ Health Policy 2015;13:595-613.

6 Chatterjee S, Laxminarayan R. Costs of surgical procedures in Indian hospitals. BMJ Open 2013;3:e002844.

7 Chauhan AS, Prinja S, Ghoshal S, et al. Cost of treatment for head and neck cancer in India. PLoS One 2018;13:e0191132.

8 Prinja S, Bahuguna P, Duseja A, et al. Cost of intensive care treatment for liver disorders at tertiary care level in India. Pharmacoecon Open 2018;2:179-90.

9 Kaur G, Prinja S, Malhotra P, et al. Cost of treatment of multiple myeloma in a public sector tertiary care hospital of North India. Indian J Hematol Blood Transfus 2018;34:25-31.

10 Prinja S, Jeet G, Verma R, et al. Economic analysis of delivering primary health care services through community health workers in 3 North Indian states. PLoS One 2014;9:e91781.

11 Prinja S, Manchanda N, Mohan P, et al. Cost of neonatal intensive care delivered through district level public hospitals in India. Indian Pediatr 2013;50:839-46.

12 Prinja S, Balasubramanian D, Jeet G, et al. Cost of delivering secondary-level health care services through public sector district hospitals in India. Indian J Med Res 2017;146:354-61.

13 Tangcharoensathien V, Limwattananon S, Patcharanarumol W, et al. Achieving universal health coverage goals in Thailand: the vital role of strategic purchasing. Health Policy Plan 2015;30:1152-61.

14 Prinja S, Selvaraj S, Muraleedharan V, et al. National health system cost database for India, 2019. Available: https://www. healtheconomics.pgisph.in/costing_web/index.php?action=gen_ secondary [Accessed 24 Aug 2019].

15 Bahuguna P, Guinness L, Sharma S, et al. Estimating the unit costs of healthcare service delivery in India: addressing information gaps for price setting and health technology assessment. Appl Health Econ Health Policy 2020;11. doi:10.1007/s40258-020-00566-9. [Epub ahead of print: 14 Mar 2020].

16 Drummond MF. Methods for the economic evaluation of health care programmes. 2 edn. Oxford: Oxford Medical Publications, 1997.

17 Özaltın A, Cashin C. Joint learning network, 2019. Available: http:// www.jointlearningnetwork.org/uploads/files/resources/JLN_Costing Toolkit_Interactive_FINAL.pdf [Accessed 24 Aug 2019].

18 GHCC. Global heath cost consortium, 2019. Available: https:// ghcosting.org/pages/standards/reference_case [Accessed 24 Aug 2019].

19 Prinja S, Gupta A, Verma R, et al. Cost of delivering health care services in public sector primary and community health centres in North India. PLoS One 2016;11:e0160986.

20 Singh PK, Kumar C, Rai RK, et al. Factors associated with maternal healthcare services utilization in nine high focus states in India: a multilevel analysis based on 14385 communities in 292 districts. Health Policy Plan 2014;29:542-59.

21 Jana A, Basu R. Examining the changing health care seeking behavior in the era of health sector reforms in India: evidences from the National Sample Surveys 2004 \& 2014. Glob Health Res Policy 2017;2:6.

22 Zurn P, Dal Poz MR, Stilwell B, et al. Imbalance in the health workforce. Hum Resour Health 2004;2:13.

23 GHCC. Global heath cost consortium, 2019. Available: https:// ghcosting.org/pages/standards/principles/resource_use_ measurement [Accessed 24 Aug 2019].

24 Rao KD, Shahrawat R, Bhatnagar A. Composition and distribution of the health workforce in India: estimates based on data from the national sample survey. WHO South East Asia J Public Health 2016;5:133-40.

25 Ram F, Shekhar C. Ranking and mapping of districts based on socio-economic and demographic indicators, 2006. Available: http:// iipsindia.org/publications05_b_13a.htm [Accessed 24 Aug 2019].

26 Kumar S. Private sector in healthcare delivery market in India: structure, growth and implications, 2015. Available: http://isid.org.in/ pdf/WP185.pdf [Accessed 24 Aug 2019].

27 Beck EJ, Harling G, Gerbase S, et al. The cost of treatment and care for people living with HIV infection: implications of published studies, 1999-2008. Curr Opin HIV AIDS 2010;5:215-24.

28 Cunnama L, Sinanovic E, Ramma L, et al. Using top-down and bottom-up costing approaches in LMICs: the case for using both to assess the incremental costs of new technologies at scale. Health Econ 2016;25:53-66.

29 HTAln. HTAIn manual, 2019. Available: http://htain.icmr.org.in/index. php/documents/publications/htain-manual [Accessed 24 Aug 2019].

30 Prinja S, Chauhan AS, Rajsekhar K, et al. Addressing the cost data gap for universal health care coverage in India: a national health system cost database for India. Value in Health Regional Issues 2020;21:226-9. 